\title{
Percutaneous Vertebroplasty: A New Serial Injection Technique to Minimize Cement Leak
}

\author{
Hossam Elnoamany \\ Neurosurgical Department, Faculty of Medicine, Menoufia University Hospital, Shebin El Kom, Egypt
}

\section{Study Design: This is a prospective cohort study.}

Purpose: This study discusses a new technique for injecting cement in the affected vertebrae.

Overview of Literature: Since introduction of vertebroplasty to clinical practice, the cement leak is considered the most frequent and hazardous complication. In literature, the cement extravasation occurred in $26 \%-97 \%$ of the cases.

Methods: A hundred and twenty-three patients underwent vertebroplasty using the serial injection technique. The package of the cement powder and the solvent was divided into five equal parts. Each part of the powder and the solvent was mixed as a single dose and injected to the affected vertebra. The duration between subsequent injections was 10 minutes. Each injection consisted of 1-1.5 $\mathrm{mL}$ of cement.

Results: This new technique gives the surgeon enough time to make multiple separate injections using the same package. The time interval between injections hardens the cement just enough so that it does not get displaced by the next cement injection. This technique gives time to the preceding injected cement to seal off the cracks and cavities in the vertebra, and subsequently leads to a significant decrease in cement leak $(p<0.001)$, as compared to literature.

Conclusions: This study demonstrates a previously unreported technique for vertebroplasty that adds more safety to the procedure by significantly decreasing cement leak. It also makes the surgeon more relaxed due to time intervals, giving him more self-confidence whilst performing the procedure.

Keywords: Osteoporotic spinal fractures; Traumatic non osteoporotic vertebral fractures; Percutaneous vertebroplasty; Serial cement injection technique; Cement leak

\section{Introduction}

Percutaneous vertebroplasty (PV) was first introduced for the treatment of vertebral angiomas in 1987 by Galibert et al. [1]. Indications were extended to osteolytic neoplasms [2-4] and osteoporotic fractures [3,5-11] in the following years. Pain relief is achieved in approximately $70 \%-100 \%$ $[12,13]$ of osteoporotic fractures. For this reason, PV is one of the most efficient procedures in spine surgery. Cement leaks are often found after PV, with reported rates between $11 \%$ and $73 \%$ [12-14]. These leaks are generally small and are usually of no clinical consequence. In healthy individuals, the lungs will tolerate small emboli without symptoms. A large cement leak, however, can cause a pulmonary infarct, and multiple emboli may lead to pulmonary compromise or even death [15]. Cement

Received Mar 13, 2015; Revised Apr 19, 2015; Accepted Apr 19, 2015

Corresponding author: Hossam Elnoamany

Neurosurgical Department, Faculty of Medicine, University Hospital, Menoufia University,

64 Gamal Abdel Nasser St., Shebin El Kom, Meuoufia, Egypt

Tel: +20-1002905305, Fax: +20-48-2233771, E-mail: hae1967@gmail.com 
can also leak into the disc space. This accounts for $25 \%$ or more of the total leaks.

The most common consequence of a severe symptomatic cement leak occurs locally, producing nerve root irritation (resulting in radiculopathy) or cord compression (resulting in myelopathy). Nerve root irritation may be transient and treatable with non-steroidal antiinflammatory drugs or local steroid injections. Persistent pain, however, may require surgical removal of the cement. Cord compression may result in paresis or paralysis. Substantial local cement leaks may also result in local pain exacerbation [16]. The purpose of this study is to introduce a new cement injection technique, and to study and analyze the incidence of cement leak during and after vertebroplasty.

\section{Materials and Methods}

\section{Patients}

A hundred and twenty-three patients were treated by vertebroplasty using the serial injection technique. Eightynine patients were suffering from osteoporotic vertebral compression fractures (VCFs) with bone mineral density -2 or less. The other thirty-four patients had posttraumatic non osteoporotic vertebral compression fractures (TNVCFs). The cement leak was detected both immediately by using $\mathrm{C}$-arm in the operating room, and postoperatively the next morning by computed tomography (CT) scans for the vertebral area (including the injected vertebra or vertebrae) as well as chest. This study was approved by the Institutional Review Board of Menoufia University. All patients provided written informed consent.

\section{Perioperative planning}

Based on the preoperative X-ray lateral view, the body of the vertebra to be injected was divided into three parts. The anteriormost and posteriormost part were of $1 \mathrm{~cm}$ width each; the rest of the vertebra formed the middle part. This middle part was further divided into five equal parts which were to be injected with cement (Fig. 1).

\section{Operative technique}

PV entails the percutaneous injection of bone cement, typically polymethyl methacrylate (PMMA), into the col- lapsed vertebral body. PV is generally performed under general anaesthesia, although the procedure can be safely performed under conscious sedation.

\section{1) Imaging technique}

After prone positioning, the X-ray tube and image-intensifier is centered over the relevant vertebral body, such that the superior and inferior endplates are aligned / not oblique, and the spinous process is in midline.

\section{2) Cannula positioning and advancement}

The current study used the cannula positioning and advancement as described earlier in literature [17].

\section{3) Cement preparation and injection technique}

The package of the powder polymer and the liquid monomer was divided into five equal parts. Each part of the powder and the solvent was mixed as a single dose to prepare cement. Once the cement had a thick toothpastelike consistency, injections commenced, using a $1 \mathrm{~mL}$ syringe. Serial injection technique was performed, with a 10 minute interval between each injection. This time interval gave the injected cement time to harden enough before the next injection was started.

Each injection consisted of 1-1.5 mL of cement; the cement is equally divided on both cannulas if bilateral approached is used. The first injection filled the fissures

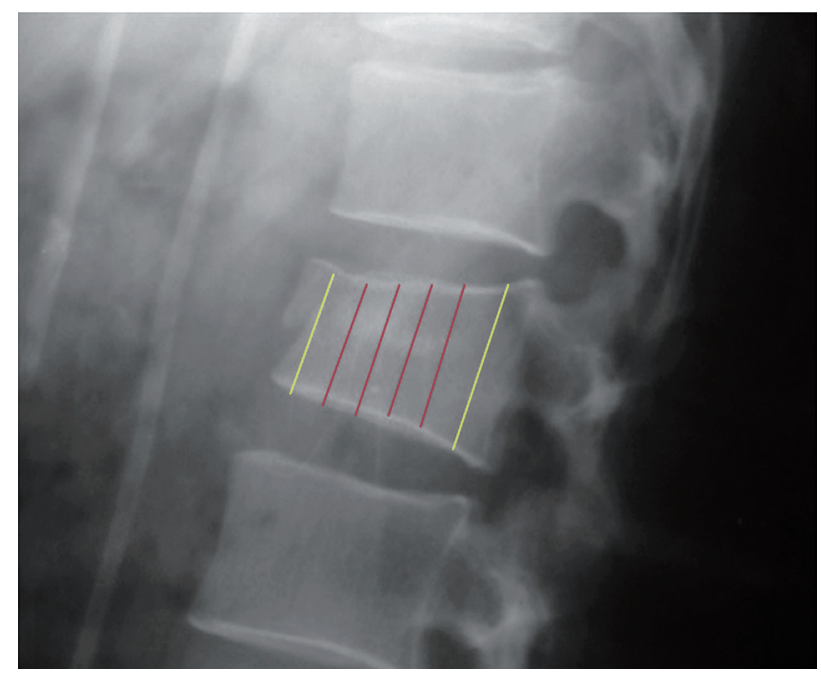

Fig. 1. Plain X-ray lateral view of the affected vertebra. The two yellow lines indicate $1 \mathrm{~cm}$ each of the anterior and posterior ends, which are not to be injected with the cement. The middle part of the vertebra is divided into five equal parts, which are to be serially injected over five injections. 
and the cracks in the anteriormost fifth segment of the planned injected area of the affected vertebra, without too much cement injection; the second was injected in the forth-fifth segment; this continued progressively till the affected vertebra was filled with cement. One needle is used per injection. In each injection, it is important not to use the injector; the cement is pushed to the affected vertebrae by using cannula stylet only, with repeated introduction of the stylet into the cannula.

\section{4) Postoperative care}

The patient remained supine for two hours, with monitoring of neurovascular status and wound inspection every 15 and 30 minutes, respectively. The patient is then gently mobilized. If the status of the patient is stable, they can be discharged to go home after an overnight hospital stay.

\section{Statistical analysis}

Results were statistically analyzed by statistical package SPSS ver. 16 (SPSS Inc., Chicago, IL, USA). Chi-squared $\left(X^{2}\right)$ and Fisher exact test were used for qualitative variables. $\mathrm{Z}$ test was used for proportions.

\section{Results}

The serial injection technique was used to operate on 123 patients. The average age of the patients was 56 years of age (range, 16 to 73 years); 47 were men and 76 were female. Of the total patients evaluated, 34 patients sustained a fracture following a trauma with 54 levels affected, and 89 had osteoporotic fractures with 142 levels affected. One level was treated in 35 patients, two levels in 49 patients, and three levels in 21 patients.

The levels treated varied, with 83/196 fractures (42.3\%) occurring at lumbar vertebra, and 113/196 (57.7\%) occurring at lower thoracic vertebra (from T8 to T12). The average cement volume injected per vertebra was $3-5 \mathrm{~mL}$ in osteoporotic cases, and $2.5-3.5 \mathrm{~mL}$ in posttraumatic cases.

Cement leak was detected in three patients by C-arm fluoroscopy immediately post procedure, whereas 11 patients with cement leakage were detected by CT scans next morning. Of the 11 patients, three patients showed prevertebral cement leak, two patients showed paravertebral leak, four patients showed intradiscal leakage, and two patients showed epidural cement leak.

\section{Case presentations}

1) Case 1

A 49-year-old female complained of low back pain with no trauma; she presented with localized tenderness in the area of thoracolumbar junction. Radiological investigations showed T12 compression fracture, and bone mineral densitometry showed osteoporotic levels. She had more than $26 \%$ anterior compression fracture of $\mathrm{T} 12$, and $15^{\circ}$ of kyphosis. She underwent PV via bilateral transpedicular approach (Fig. 2).

\section{2) Case 2}

A 21-year-old male complained of lower back pain after falling from a height. Radiological investigations showed L1 compression fracture, and bone mineral densitometry showed normal levels. He had more than 33\% anterior compression fracture of L1, and $18^{\circ}$ of kyphosis. He underwent PV via unilateral transpedicular approach (Fig. 3).

\section{Discussion}

During my early practice and while observing the vertebroplasty practitioners, it was noticed that the most important factors that increased the incidence of cement leak were: (1) inadequate cement opacification and (2) a hurry to inject the proper amount of cement before cement hardening. This is raised by the report of La Maida et al. [18] in which $43 \%$ of their patients had cement leakage; of these, $67 \%$ had received treatment with vertebroplasty for multiple vertebrae.

This made me start performing the current technique of serial cement injection, with a follow up to detect incidence of cement leak by fluoroscopy immediately after performing $\mathrm{PV}$, and the next morning by performing $\mathrm{CT}$ scans, before discharging the patient.

The decision to select 10 minute interval as optimal was based on the following observations. At first, I examined the cement hardening time outside the human body, after mixing the polymer with the monomer. The following changes were noted: the cement became a tough paste after nearly 10 minutes; it continued to harden, and became very hard after about 25 minutes. Injecting cement earlier than 10 minutes might lead to more cement leak, as the cement would still be a soft paste; conversely, if the cement is injected later than 10 minutes, the cement will be 

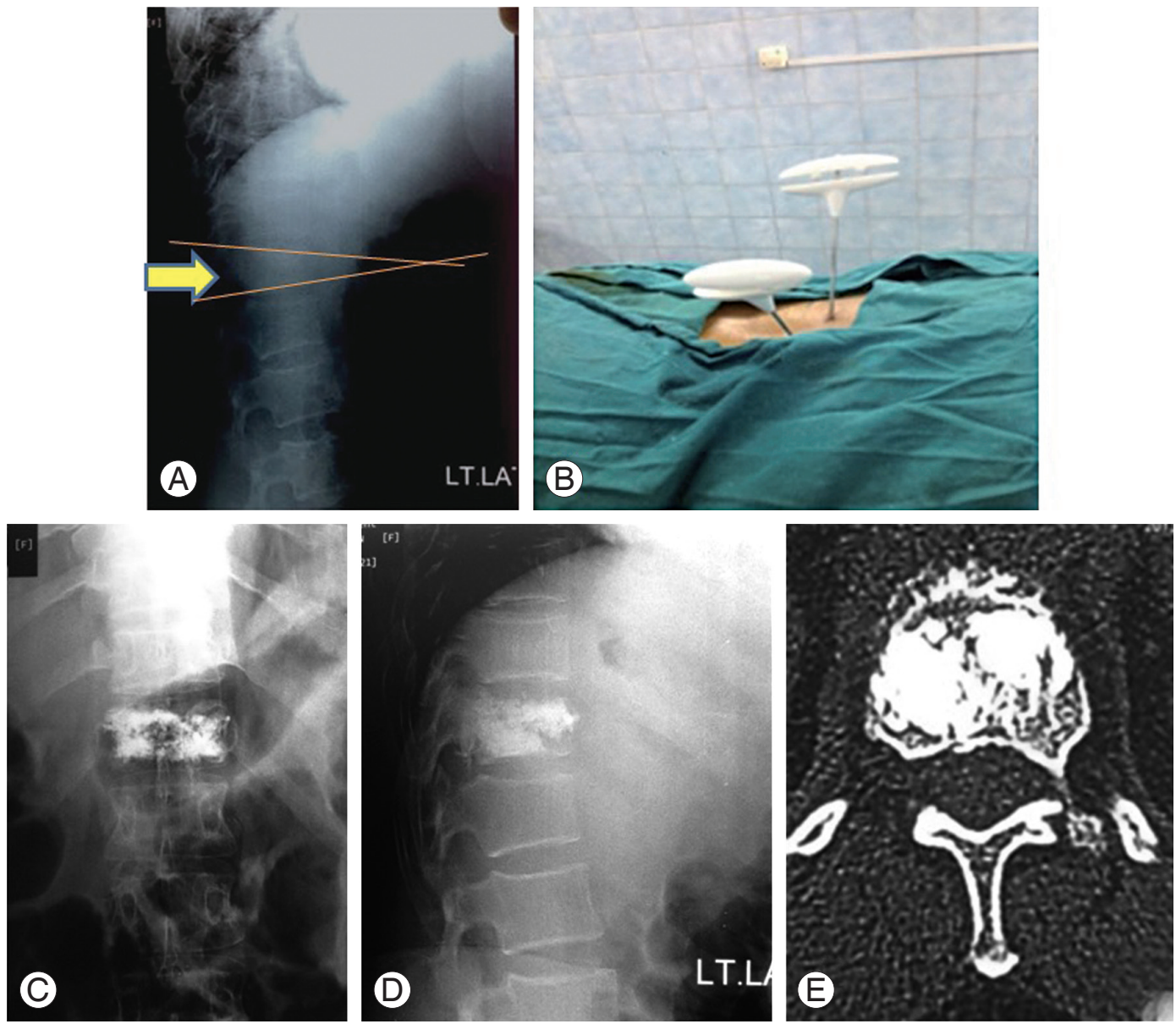

Fig. 2. (A) Lateral plain X-ray shows fracture of $T 12$ with $15^{\circ}$ of kyphosis. (B) Intraoperative $X$-ray showing bilateral transpedicular approach. (C) X-ray (anteroposterior view) post percutaneous vertebroplasty (PV) showing T12 filled with injected cement. (D) X-ray (lateral view) post PV showing T12 filled with injected cement. (E) Post PV computed tomography scans: axial view shows good cement filling in the T12 vertebra with minimal leak into epidural venous plexus (asymptomatic leak).
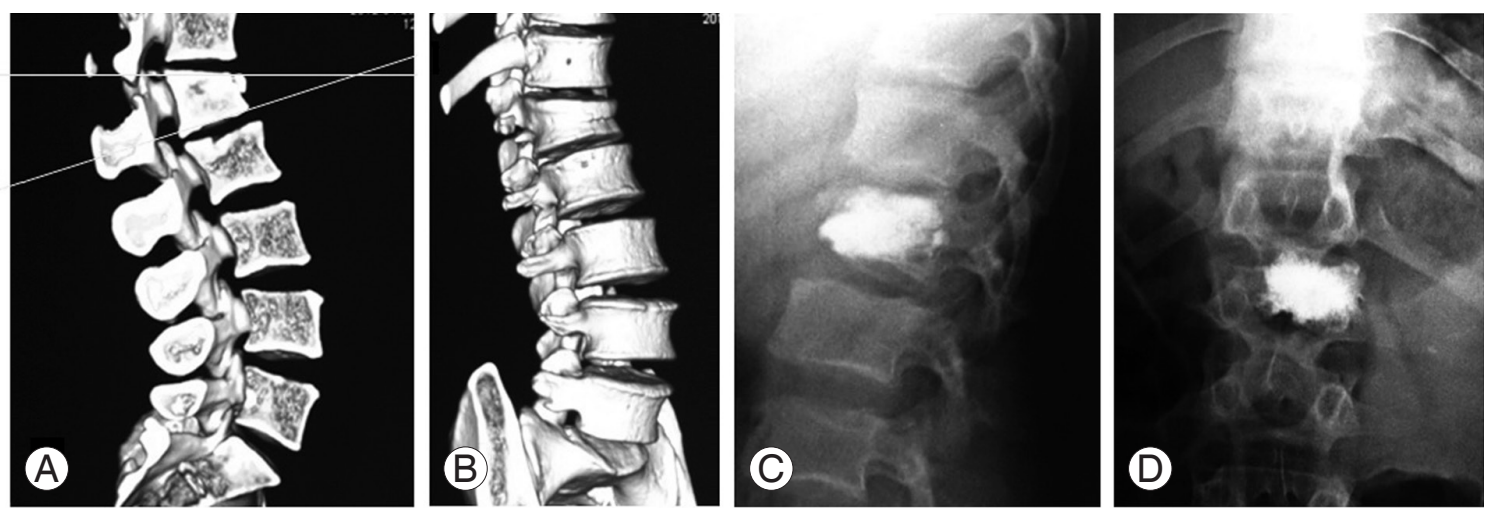

Fig. 3. (A, B) Reconstruction computed tomography scans show fracture L1 with $18^{\circ}$ of kyphosis. (C) Plain X-ray (lateral view) showing properly filled L1 vertebra with cement. (D) Plain X-ray (anteroposterior view) showing the filled L1 vertebra from unilateral approach, with the cement traversing the midline and filling more than $25 \%$ of the contra-lateral side.

much more hard, and it would be difficult to inject without the injector, which applies too much pressure thus leading to cement leak. Also, the hardened cement would lead to the improper cement shaping within the vertebral 
Table 1. Show the percentage of cement leak in VCFs in this study and in literature and its significance

\begin{tabular}{|c|c|c|c|c|c|}
\hline \multirow[b]{2}{*}{ Leak } & \multicolumn{3}{|c|}{ Osteoporotic patient } & \multirow[b]{2}{*}{$x^{2}$} & \multirow[b]{2}{*}{$p$-value } \\
\hline & $\begin{array}{l}\text { Current study } \\
\qquad(\mathrm{n}=89)\end{array}$ & $\begin{array}{l}\text { Martin et al. [25] } \\
\qquad(n=181)\end{array}$ & $\begin{array}{l}\text { Yeom et al. [11] } \\
\qquad(n=49)\end{array}$ & & \\
\hline Yes & $7(7.9)$ & $149(82.3)$ & 42 (85.7) & Current vs. Martin, 135.58 & $<0.001^{\text {a) }}$ \\
\hline No & $82(92.1)$ & $32(17.7)$ & $7(14.3)$ & Current vs. Yeom, 83.63 & $<0.001^{\text {a) }}$ \\
\hline
\end{tabular}

VCF, vertebral compression fracture.

a)Highly significant.

cavities and cracks.

Thus, the 10 minutes interval was selected because the cement injected in the first injection cannot be displaced by the next injected cement, and this subsequently minimizes cement leak. Also, using the stylet of the cannula instead of the injector plays an important role in minimizing cement leak as the exerted pressure on the previously injected cement in the affected vertebra was very minimal. This technique also leads to good shaping of the cement inside the vertebra, with a resultant good vertebral filling.

Serial cement injection was ceased once the body of the affected vertebra is filled with cement. The amount of the injected cement varied from one vertebra to another, and from osteoporotic bone to nonosteoporotic one.

The current serial injection technique provides the surgeon to have time to prepare each injection separately, and to allow good cement opacification before injection. This technique also gives the surgeon the proper time after each injection to clearly visualize the injected cement. The small amount of the cement injected each time helps in filling only the cracks first, before it starts filling the spaces and cavities in the vertebra.

In 2005, Schmidt et al. [19] reported that the rate of cement leakage during vertebroplasty is quite high, if precise determination by CT scan had been done. They concluded that for accurate determination of multiple cement leakage, CT scans should be considered as the method of choice. In the VERTOS II trial, the authors reported that late cement migration during follow-up did not occur, thus rendering the standard postprocedural CT of the treated vertebral body in PV as not necessary [20].

In current study, all the patients were evaluated intraoperatively by fluoroscopy, and postoperatively by CT scans the next day, to detect precise cement leaks. Cement leak was detected in only 3 patients by fluoroscopy, but in postoperative CT scans next day, 11 patients revealed ce- ment leakage.

In general, PV is a safe procedure which is well tolerated. The overall complication rate in PV for VCFs as reported in the literature is low, ranging from $1 \%$ to $10 \%$ [7,21-23]. The most common complication of PV is cement extravasation, with an occurrence of $26 \%-97 \%$ [24]. In the current study, only seven cases (7.9\%) out of 89 patients treated for osteoporotic VCFs had cement leak detected by CT scans. This result was highly significant $(p<0.001)$ as compared to that reported previously in literature $[11,25]$ (Table 1). I believe that this highly significant result is related to the new serial injection technique which minimizes the cement leak. Pushing a very small amount of cement in each injection using the cannula stylet, and the time interval between subsequent injections, are the cornerstone of the success of this new serial injection technique.

Among the 34 patients treated for TNVCFs, only four patients (11.8\%) had cement leak detected by CT scans. This result, although less than the previous report by Knavel et al. [26], was statistically insignificant $(p=0.109)$, probably because of the small number of patients in this study (Table 2).

The vast majority of leaks are asymptomatic. However, cement leaks can narrow and/or impinge neural structures, either within the neural foramina or the epidural space. Radiculopathy related to cement leakage is usually transient and responds well to systemic analgesia and/ or transforaminal nerve block, although occasional cases requiring surgical decompression have been reported $[27,28]$. In the present study, no cases with neural compromise had been detected by CT scans post procedure. All 11 cases with cement leak in this study were asymptomatic. This overall result is significant when compared to the results of Evans et al. [24], who reported $4.9 \%$ of his 245 patients who complained from symptomatic cement 
Table 2. Show the percentage of cement leak in posttraumatic non osteoporotic compression fractures in this study and in literature and its significance

\begin{tabular}{lccc} 
& \multicolumn{2}{c}{ Posttrauma patient } & \\
\cline { 2 - 3 } Leak & Current study $(\mathrm{n}=34)$ & Knavel et al. [26] $(\mathrm{n}=15)$ & \\
Yes & $4(11.8)$ & $5(33.3)$ & $0.109^{\mathrm{a})}$ \\
No & $30(88.2)$ & $10(66.7)$ & \\
\hline
\end{tabular}

Values are presented as number (\%).

a) Fisher exact, non significant.

Table 3. Show the percentage of symptomatic cement leak in this study and in literature and its significance

\begin{tabular}{ccccc} 
& Current study $(\mathrm{n}=123)$ & Evans et al. [24] $(\mathrm{n}=245)$ & Z test & $p$-value \\
Symptomatic leak & $0 \%$ & $4.9 \%$ & 2.19 & $0.028^{\mathrm{a})}$ \\
\hline
\end{tabular}

a) Significant.

leak post vertebroplasty (Table 3).

This new serial injection technique gives the surgeon enough time to make multiple separate injections with the same package. The time interval between injections hardens the cement just enough so as not to get displaced by the next cement injection. This technique of injection also gives time to the injected cement to seal off the cracks in the anteriormost fifth segment of the affected area, before starting to fill any cavity present in the second adjoining segment, and continuing this way till all segments are cemented. This serial injection technique subsequently leads to a highly significant decrease in cement leak $(p<0.001)$ as compared to the incidence reported in literature.

Systemic cement embolisation is rare, with one study estimating as much as $5 \%$ of patients may undergo cement pulmonary embolism [29]. These are rarely clinically significant [15]. In this study, no case of pulmonary embolism was detected.

\section{Conclusions}

This study demonstrates a previously unreported serial injection technique for vertebroplasty that adds more safety to the procedure by significantly decreasing cement leak. It also gives the surgeon much more relaxation time and self-confidence during the procedure. The only disadvantage of this technique is that it takes much more time than reported before; however, this correlates positively to a better outcome and the wellbeing of the patient.

\section{Conflict of Interest}

No potential conflict of interest relevant to this article was reported.

\section{Acknowledgments}

Thanks to Dr. Zeinab Abdel Aziz Kasemy, Lecturer of Public Health and Community Medicine, Menoufia University, for doing statistics in this study.

\section{References}

1. Galibert P, Deramond H, Rosat P, Le Gars D. Preliminary note on the treatment of vertebral angioma by percutaneous acrylic vertebroplasty. Neurochirurgie 1987;33:166-8.

2. Alvarez L, Perez-Higueras A, Quinones D, Calvo E, Rossi RE. Vertebroplasty in the treatment of vertebral tumors: postprocedural outcome and quality of life. Eur Spine J 2003;12:356-60.

3. Barr JD, Barr MS, Lemley TJ, McCann RM. Percutaneous vertebroplasty for pain relief and spinal stabilization. Spine (Phila Pa 1976) 2000;25:923-8.

4. Fourney DR, Schomer DF, Nader R, et al. Percutaneous vertebroplasty and kyphoplasty for painful vertebral body fractures in cancer patients. J Neurosurg 2003;98(1 Suppl):21-30.

5. Deramond H, Depriester C, Galibert P, Le Gars D. Percutaneous vertebroplasty with polymethylmeth- 
acrylate. Technique, indications, and results. Radiol Clin North Am 1998;36:533-46.

6. Diamond TH, Champion B, Clark WA. Management of acute osteoporotic vertebral fractures: a nonrandomized trial comparing percutaneous vertebroplasty with conservative therapy. Am J Med 2003;114:25765.

7. Jensen ME, Evans AJ, Mathis JM, Kallmes DF, Cloft HJ, Dion JE. Percutaneous polymethylmethacrylate vertebroplasty in the treatment of osteoporotic vertebral body compression fractures: technical aspects. AJNR Am J Neuroradiol 1997;18:1897-904.

8. Lane JI, Maus TP, Wald JT, Thielen KR, Bobra S, Luetmer PH. Intravertebral clefts opacified during vertebroplasty: pathogenesis, technical implications, and prognostic significance. AJNR Am J Neuroradiol 2002;23:1642-6.

9. Martin JB, Jean B, Sugiu K, et al. Vertebroplasty: clinical experience and follow-up results. Bone 1999;25(2 Suppl):11S-15S.

10. McGraw JK, Lippert JA, Minkus KD, Rami PM, Davis TM, Budzik RF. Prospective evaluation of pain relief in 100 patients undergoing percutaneous vertebroplasty: results and follow-up. J Vasc Interv Radiol 2002;13(9 Pt 1):883-6.

11. Yeom JS, Kim WJ, Choy WS, Lee CK, Chang BS, Kang JW. Leakage of cement in percutaneous transpedicular vertebroplasty for painful osteoporotic compression fractures. J Bone Joint Surg Br 2003;85: 83-9.

12. Garfin SR, Yuan HA, Reiley MA. New technologies in spine: kyphoplasty and vertebroplasty for the treatment of painful osteoporotic compression fractures. Spine (Phila Pa 1976) 2001;26:1511-5.

13. Watts NB, Harris ST, Genant HK. Treatment of painful osteoporotic vertebral fractures with percutaneous vertebroplasty or kyphoplasty. Osteoporos Int 2001;12:429-37.

14. Shapiro S, Abel T, Purvines S. Surgical removal of epidural and intradural polymethylmethacrylate extravasation complicating percutaneous vertebroplasty for an osteoporotic lumbar compression fracture: case report. J Neurosurg 2003;98(1 Suppl):90-2.

15. Padovani B, Kasriel O, Brunner P, Peretti-Viton P. Pulmonary embolism caused by acrylic cement: a rare complication of percutaneous vertebroplasty. AJNR Am J Neuroradiol 1999;20:375-7.
16. Mathis JM. Percutaneous vertebroplasty: complication avoidance and technique optimization. AJNR Am J Neuroradiol 2003;24:1697-706.

17. Nairn RJ, Binkhamis S, Sheikh A. Current perspectives on percutaneous vertebroplasty: current evidence/controversies, patient selection and assessment, and technique and complications. Radiol Res Pract 2011;2011:175079.

18. La Maida GA, Giarratana LS, Acerbi A, Ferrari V, Mineo GV, Misaggi B. Cement leakage: safety of minimally invasive surgical techniques in the treatment of multiple myeloma vertebral lesions. Eur Spine J 2012;21 Suppl 1:S61-8.

19. Schmidt R, Cakir B, Mattes T, Wegener M, Puhl W, Richter M. Cement leakage during vertebroplasty: an underestimated problem? Eur Spine J 2005;14:46673.

20. Venmans A, Klazen CA, van Rooij WJ, de Vries J, Mali WP, Lohle PN. Postprocedural CT for perivertebral cement leakage in percutaneous vertebroplasty is not necessary: results from VERTOS II. Neuroradiology 2011;53:19-22.

21. Cyteval C, Sarrabere MP, Roux JO, et al. Acute osteoporotic vertebral collapse: open study on percutaneous injection of acrylic surgical cement in 20 patients. AJR Am J Roentgenol 1999;173:1685-90.

22. Mathis JM, Barr JD, Belkoff SM, Barr MS, Jensen ME, Deramond H. Percutaneous vertebroplasty: a developing standard of care for vertebral compression fractures. AJNR Am J Neuroradiol 2001;22:37381.

23. Chiras J, Depriester C, Weill A, Sola-Martinez MT, Deramond H. Percutaneous vertebral surgery: technics and indications. J Neuroradiol 1997;24:45-59.

24. Evans AJ, Jensen ME, Kip KE, et al. Vertebral compression fractures: pain reduction and improvement in functional mobility after percutaneous polymethylmethacrylate vertebroplasty retrospective report of 245 cases. Radiology 2003;226:366-72.

25. Martin DJ, Rad AE, Kallmes DF. Prevalence of extravertebral cement leakage after vertebroplasty: procedural documentation versus CT detection. Acta Radiol 2012;53:569-72.

26. Knavel EM, Thielen KR, Kallmes DF. Vertebroplasty for the treatment of traumatic nonosteoporotic compression fractures. AJNR Am J Neuroradiol 2009;30:323-7. 
27. Harrington KD. Major neurological complications following percutaneous vertebroplasty with polymethylmethacrylate: a case report. J Bone Joint Surg Am 2001;83:1070-3.

28. Ratliff J, Nguyen T, Heiss J. Root and spinal cord compression from methylmethacrylate vertebroplasty.
Spine (Phila Pa 1976) 2001;26:E300-2.

29. Choe DH, Marom EM, Ahrar K, Truong MT, Madewell JE. Pulmonary embolism of polymethyl methacrylate during percutaneous vertebroplasty and kyphoplasty. AJR Am J Roentgenol 2004;183:1097102. 